\title{
INFÂNCIAS MIGRANTES, EDUCAÇÃO INFANTIL, TERRITORIALIDADES: OS MOVIMENTOS DE DESTERRITORIALIZAÇÃO E RETERRITORIALIZAÇÃO DAS CRIANÇAS POMERANAS
}

\author{
Rosali Rauta Siller \\ Universidade Federal do Espírito Santo (UFES), Vitória, Espírito Santo, Brasil
}

\begin{abstract}
Resumo: Este artigo, sob a forma de ensaio, busca compreender os movimentos de desterritorialização das crianças pomeranas do seu território de origem, a Pomerânia, e de reterritorialização, em seu território de destino, neste caso, Santa Maria de Jetibá-ES. O território é compreendido a partir de Sayad (1998) e de Haesbaert $(2014,2020)$, em uma perspectiva integradora. O texto destaca a desterritorialização como processo que faz parte dos movimentos migratórios dos quais as crianças pomeranas participaram. Aponta para a importância de o debate sobre educação infantil contemplar as crianças migrantes, em especial as pomeranas, para que possam se reconhecer com suas línguas, fazeres e saberes ancestrais, superando práticas hierarquizadas que têm contribuído para legitimar múltiplas desigualdades desde a Educação Infantil.
\end{abstract}

Palavras-chave: Crianças Pomeranas. Imigração. Territorialidade.

\section{INTRODUÇÃO}

Por que trazer a temática das migrações para o campo da Educação Infantil? Compreender como emergiu meu interesse por essa temática exigiu-me o esforço de rememorar e refletir sobre a minha trajetória de vida pessoal e acadêmica. Nesse processo, acabei reencontrando a minha própria história, marcada pela "diáspora", empurrada pelas estradas, em busca de um lugar para viver e prosseguir meus estudos. Nessa caminhada, aprendi lentamente, desde muito pequena, a me ver como uma "estrangeira" em meu próprio lugar.

Ao tratar das causas da diáspora, Hall (2003) enumera a pobreza, o subdesenvolvimento, a falta de oportunidades, os legados imperialistas, os quais levam ao espalhamento, à dispersão das pessoas. No meu caso, foram as oportunidades de emprego e de trabalho, logo, questões de ordem econômica, que fizeram com que eu passasse parte de minha vida, desde a minha infância, vivenciando os processos migratórios.

Nesse movimento, desterritorializei-me dos lugares de partida, reterritorializando-me, todavia, nos lugares de chegada. Dou-me conta de que essa situação de "migrante" atravessou minha trajetória de vida pessoal, acadêmica e profissional. Desse percurso, destacarei neste aqui as situações que julguei as mais significativas e que poderão levar o leitor à compreensão do lugar de onde falo e das inquietações com as quais me deparo. 
Visto que discuto neste texto as vulnerabilidades a que as crianças pomeranas estão submetidas por serem imigrantes, o primeiro ponto a destacar é como cheguei ao território pomerano. Ao concluir o curso de Pedagogia na Universidade Federal do Espírito Santo (UFES), fui convidada a trabalhar no município de Santa Leopoldina. Esta foi a cidade para onde me mudei aos seis anos de idade, de onde saí com toda a minha família - constituída por pai, mãe e 11 filhos(as) rumo ao município de Vila Velha, no mesmo estado, quando ainda cursava a oitava série do Ensino Fundamental. Voltei para aquela região, como moradora, em 1989, desta vez, para o município de Santa Maria de Jetibá, que havia se emancipado naquele ano, desvinculando-se politicamente de Santa Leopoldina.

Uma das particularidades observadas no território de Santa Maria de Jetibá, onde resido até hoje, é a presença de crianças pomeranas, visto que a cidade é um dos redutos de imigrantes pomeranos que chegaram ao Brasil em meados do século XIX. Essas crianças chegam às creches e pré-escolas monolíngues: falam apenas sua língua materna, a língua pomerana, com a qual aprendem um modo de vida específico, ainda fortemente vinculado aos primeiros imigrantes da Pomerânia que se deslocaram para cá.

No território de Santa Maria de Jetibá, elas compartilham um passado comum, um grau de coesão grupal, verificado não só pelo uso da língua pomerana, como também pela religião luterana, pela agricultura familiar desenvolvida na pequena propriedade. Tais características são marcas identitárias do povo tradicional pomerano, diferenciando-o de outros grupos étnicos ali residentes.

Quando passei a viver nesse território, aos meus olhos, essas eram particularidades muito distintas dos demais povos que eu conhecia e com os quais convivia até então. Não obstante, com os fluxos migratórios interestaduais que têm ocorrido nos últimos anos, esse território até então "homogêneo", ainda que tenha fortes raízes pomeranas, vai se transformando. Nessa direção, ganha novas configurações, verificadas principalmente com os seus modos de vida, mas também com a ocupação desordenada do espaço. Imersa neste contexto de imigração pomerana e de migrações interestaduais, surge o meu interesse pela temática das migrações com foco nas infâncias pomeranas.

Esse contexto migratório permitiu-me desnudar a ideia de uma suposta concepção universal de infância, alicerçada na perspectiva eurocêntrica ocidental, na qual se ancora a leitura que nós, adultos, fizemos durante tanto tempo e ainda insistimos fazer sobre o que é infância. Nessa concepção, as crianças não se diferenciam, em nenhum aspecto - econômico, social, linguístico, cultural.

Ora, trata-se de visão equivocada, pois está subsidiada no entendimento de que o Brasil seria um país homogêneo, que tem como padrão uma identidade nacional. Essa identidade faz referência a uma classe social, a uma etnia, a uma raça, a uma língua, a uma cultura, a um território que, de maneira estrutural, posiciona crianças que se diferenciam desse padrão em condição de desigualdades e de subalternização numa sociedade na qual estão arraigadas fortes marcas do patriarcado, do capitalismo e do colonialismo. 
SILLER, R. R.

Produzido pela modernidade, esse processo histórico de homogeneização, "naturalização" e normatização do que é infância conseguiu ocultar os fatores que heterogeneizam as infâncias brasileiras. Essa heterogeneidade se legitima no fato de que o Brasil é um país eminentemente pluriétnico, pluricultural, plurilíngue, um território em que pisam populações tão distintas: indígenas, afrodescendentes, populações de diferentes grupos étnicos, trazidas por fluxos migratórios impulsionados pelas desigualdades sociais, populações miscigenadas.

Isso posto, seguir a trilha da compreensão universal de infância, na qual as crianças não são tomadas em suas diferenças, culminaria, conforme entendo, no erro histórico de minimizar as diferenças e aprofundar as desigualdades. Essa criança, apresentada no padrão homogêneo, de abstrata não tem nada: é branca, de origem europeia, de classe social mais abastada, integra uma família consanguínea, é urbana, fala o português. É a criança do sistema hegemônico, uma metáfora, uma invenção da modernidade, representa falsamente um suposto universalismo que serviu para tentar suprimir diferenças, "naturalizar", normalizar e subalternizar milhares de crianças brasileiras que não se encaixam nesse padrão. Na sua pluralidade, essas crianças fogem à regra de ser uma criança definida e imposta por um modelo que apaga a diversidade de sua língua, do seu modo de ser, de dançar, de viver, que apaga experiências marcantes de sua existência.

Feitas essas considerações iniciais, pergunto: em um país marcado por uma história de migrações, caracterizado pela tradição de receber imigrantes de todas as partes do mundo, quais os impactos dessa tentativa de homogeneização da infância na vida das crianças, em especial das crianças pomeranas? Em seus movimentos de desterritorialização, será que foram bem recebidas e acolhidas em seu território de destino? Para responder à questão formulada, este ensaio busca compreender os movimentos de desterritorialização das crianças pomeranas do seu território de origem, a Pomerânia, e os movimentos de reterritorialização em seu território de destino, Santa Maria de Jetibá.

Além desta seção introdutória e das considerações finais, este texto está organizado em outras duas partes. Na primeira, procuro compreender a imigração como um movimento de territorialização sob a ótica do território, a partir dos estudos de Sayad (1998) e de Haesbaert (2014; 2020). Em seguida, discorro sobre os processos de desterritorialização das crianças pomeranas da Pomerânia e da reterritorialização em Santa Maria de Jetibá.

\section{A IMIGRAÇÃO COMO UM MOVIMENTO DE TERRITORIALIZAÇÃO SOB A ÓTICA DO TERRITÓRIO}

A partir dos estudos de Sayad (1988), a pressuposição, neste texto, é de que na origem da imigração encontramos seu ato inicial, pois "o imigrante, antes de "nascer" para a imigração, é, primeiro, um emigrante" (SAYAD, 1988, p. 18). Assim, compreendemos os fenômenos emigração e imigração na sua relação dialética, como duas faces de um mesmo processo. São os fatores estruturais conjunturais econômicos, políticos, culturais e/ou ambientais - que ocorrem em diferentes lugares e períodos que delineiam, de um lado, os fatores de expulsão do país de origem e, de outro, os fatores de atração existentes no país de acolhimento. $A$ isso somam-se os fatores subjetivos, pois a situação de quem migra é vivida e enfrentada em nível pessoal. 
Esse conjunto de aspectos determina os fluxos migratórios (LANG, 2002) no e pelomundo.

Falar da imigração é, portanto, falar da sociedade como um todo, em todas as duas dimensões: diacrônica, pondo a lupa sobre fenômenos que ocorrem com a evolução do tempo, e sincrônica, examinando fatos específicos, pontuais, concomitantes e contemporâneos. A imigração, desse modo, mostra-se como fenômeno complexo que, ao ser abordado, requer uma perspectiva que integre questões sociais, políticas, econômicas, culturais e jurídicas, as quais revelam a situação dos países e regiões de origem e de chegada dos imigrantes, em cada período histórico.

Por esse prisma, a imigração deve ser olhada como um "fato social total" (MAUSS, 2003). Apropriando-se desse conceito antropológico, Sayad (1988) dirá que a imigração é um fato social completo, o que implica considerar os sentidos da imigração também na voz dos sujeitos que vivenciam experiências migratórias. Sua interpretação indica, ainda que

[...] todo o itinerário do imigrante é, pode-se dizer, um itinerário que se dá, de certa forma, no cruzamento das ciências sociais, como um ponto de encontro de inúmeras disciplinas, história, geografia, demografia, economia, direito, sociologia, psicologia e psicologia social e até mesmo das ciências cognitivas, antropologia em suas diversas formas (social, cultural, políticas, econômicas, jurídicas, etc.), linguísticas e sociolinguísticas, ciência política etc (SAYAD, 1988, p. 15).

Falar de migrações implica falar das configurações territoriais, visto que o ato de migrar é exatamente deslocar-se de um a outro território. Como bem afirma Sayad (2000, p. 11), "emigrar e imigrar é, antes de mais nada (sic), mudar-se de espaço, de território". Portanto, para o estudo das migrações, é importante compreender a concepção de território formulada por este autor, a qual assumimos aqui. Para Haesbaert (2014, p. 28), o termo território, desde sua origem,

nasce com uma dupla conotação, material e simbólica, pois etimologicamente aparece tão próximo da terra - territorium quanto de térreo - terrolar (terror, aterrorizar), ou seja, tem a ver com dominação (jurídico-política) de terra e com a inspiração do terror, do medo, especialmente para aqueles que, com esta dominação, ficam alijados da terra, ou no "territorium" são impedidos de entrar. Ao mesmo tempo, por extensão, podemos dizer que, para aqueles que têm o privilégio de usufruí-lo, o território inspira a identificação (positiva) e a efetiva apropriação.

Assim, assumindo a concepção apresentada pelo autor, desde a sua origem, em qualquer acepção, território envolve sempre relação de poder; poder que engloba tanto a dominação política e econômica quanto a apropriação simbólico-cultural de um determinado grupo ao espaço no qual se insere. Em uma "perspectiva integradora", Haesbaert (2004) incorpora ao conceito de território as múltiplas dimensões da 
SILLER, R. R.

sociedade (culturais, políticas, econômicas, dentre outras), considerando a natureza, pois tais dimensões encontram-se intimamente ligadas à territorialidade, aos modos como as pessoas fazem uso da terra, organizam-se no espaço e atribuem significados aos lugares.

Para uma melhor compreensão, as vertentes definidoras do território, são apresentadas separadamente por Haesbaert (2004), porém, sua análise se baseia em uma concepção integradora de território que abarca as seguintes esferas:

\begin{abstract}
- Política (referida às relações espaço-poder em geral) ou jurídicopolítica (relativa também a todas as relações espaço-poder institucionalizadas): a mais difundida, onde o território é visto como um espaço delimitado e controlado, através do qual se exerce um determinado poder, na maioria das vezes - mas não exclusivamente - relacionado ao poder político do Estado.

- Cultural (muitas vezes culturalista) ou simbólico-cultural: prioriza a dimensão simbólica e mais subjetiva, em que o território é visto sobretudo, como o produto da apropriação/valorização simbólica de um grupo em relação ao seu espaço vivido.

- Econômica (muitas vezes economicista): menos difundida, enfatiza a dimensão espacial) das relações econômicas, o território como fonte de recursos e/ou incorporado no embate entre classes sociais e na relação capital-trabalho, como produto da divisão "territorial" do trabalho, por exemplo (HAESBAERT, 2020, p. 40).
\end{abstract}

A essas dimensões, posteriormente, o autor acrescenta ainda uma interpretação naturalista, que se utiliza de "[...] uma noção de território com base nas relações entre sociedade e natureza, especialmente no que se refere ao comportamento 'natural' dos homens em relação ao seu ambiente físico" (HAESBAERT, 2020, p. 40).

A partir dessa perspectiva, podemos afirmar que a desterritorialização é um processo que faz parte dos movimentos migratórios dos quais as crianças participam. Todavia, Haesbaert (2020) considera a desterritorialização como um mito, pois o que ocorre de fato é uma reterritorialização em outros espaços, mesmo que ela seja apenas em caráter funcional. Ainda assim, desterritorialização e reterritorialização, assevera o autor, devem ser percebidos na sua indissociabilidade.

Ao saírem de seus territórios de origem por motivos econômicos, políticos, culturais, sociais ou ambientais, os imigrantes sofrem um processo de desterritorialização, na medida em que são obrigados a abandonar suas origens, suas amizades, parentes, vizinhanças, escolas etc. Por outro lado, ao se instalarem em seu território de destino, muitas vezes, tão diferentes do território de sua procedência, buscam se reterritorializar, apropriando-se e produzindo novos significados nesses espaços. A reterritorialização desse grupo social está intimamente vinculada ao sentimento de pertencimento, de identidade territorial.

Nesses movimentos, é preciso considerar as inquietações sentidas pelos imigrantes, as marcas que trazem consigo, as quais são, sempre, marcas das relações que estabeleceram em outro espaço-tempo vivido, em outro território, e que dificilmente serão esquecidas, conforme argumenta Mondardo (2012, p. 46):

[...] nos territórios de saída (abandono do território de origem) um movimento e/ou situação de inquietação e, por outro lado, 
desperta e/ou provoca no encontro com o território novo (chegado) outro sentimento de inquietação). Há o desprendimento de suas raízes daquele recorte espacial no qual o/a migrante viveu parte da sua vida.

É preciso, ainda, considerar que, nesses movimentos, pode ser que "alguns territorializam numa razoável integração entre dominação e apropriação, outros podem estar territorializados basicamente pelo viés da dominação, num sentido mais funcional, não apropriativo" (MONDARDO, 2012, p. 40). Para que a territorialização se efetive, é preciso um esforço coletivo de um grupo social para ocupar, controlar e usar um ambiente físico, identificando-se com o território.

As crianças territorializadas, na perspectiva dessa discussão, são aquelas que participam do território em todas as suas dimensões (econômica, política, cultural, ambiental). Deixar de participar ou partilhar do território em algum de seus aspectos, segundo Haesbaert (2020), não desemboca na desterritorialização de forma definitiva, mas propicia a reterritorialização. Em suas territorialidades, por meio de suas características individuais ou de características de seu grupo étnico - manifestadas pela língua, festas, danças, culinária, religião, monumentos, produtos e técnicas agrícolas, dentre outros elementos -, elas constroem e ressignificam o território onde vivem.

Isso posto, corroborando Haesbaert (2020, p. 146), não é possível falar de migração em seu sentido genérico, o que "[...] pode mesmo tornar-se temerário [...]", pois "[...] há tantos tipos de migrantes quanto de indivíduos ou grupos sociais envolvidos nos processos migratórios", de modo que "somos sempre obrigados a qualificá-la [referindose à migração]". Nesses movimentos, há uma pluralidade de crianças migrantes envolvidas, as quais vivenciam suas infâncias das mais distintas formas. Assim, é importante identificar quem são as crianças envolvidas nas migrações. Por isso, a seguir, apresentamos as crianças pomeranas.

CRIANÇAS POMERANAS DO CAMPO: "ESTRANHAS", "ESTRANGEIRAS" NO TERRITÓRIO BRASILEIRO? UMA ANÁLISE NA PERSPECTIVA DA INTERSECCCIONALIDADE

Quem são as crianças pomeranas? As crianças pomeranas, das quais trata este ensaio, são sujeitos sociais e culturais, incluídas entre os Povos e Comunidades Tradicionais, situando-se entre os grupos que se reconhecem culturalmente diferenciados, que ocupam e usam territórios e recursos naturais como condição para sua reprodução nas dimensões cultural, religiosa, ancestral e econômica, fazendo uso da língua, saberes, práticas geradas e transmitidas pela tradição (BRASIL, 2007, acesso em 30 mai. 2021). São crianças que vivem em áreas rurais do município de Santa Maria Jetibá, ${ }^{1}$ que teve origem em meados do século XIX com a chegada, em 1859, dos primeiros pomeranos, provenientes da Pomerânia. ${ }^{2}$ Seus pais e mães, como também outros que lhes antecederam, são camponeses que se caracterizam, principalmente, pela prática da agricultura familiar, ${ }^{3}$ diversificada e distinta da monocultura dos grandes latifúndios.

Ao emigrarem da Pomerânia, as crianças pomeranas e suas famílias vivenciaram processos de desterritorialização e reterritorialização, em um movimento contínuo e 
SILLER, R. R.

dialético de construção e reconstrução, de fazer-se e refazer-se, em meio a rupturas, mudanças e permanências. Deixaram para trás um universo simbólico, suas territorialidades primeiras, que ainda hoje as conectam à Pomerânia de onde se originaram, mas que foram ressignificadas no território de destino, compondo novas territorialidades. A partir das atividades cotidianas, como o trabalho familiar na pequena propriedade, as territorialidades se concretizam no movimento de reprodução do território pomerano no novo espaço, envolvendo características simbólico-culturais produzidas, reproduzidas e ressignificadas pelas crianças e pelos seus familiares, bem como pelos demais de seu grupo étnico-cultural. A língua pomerana, os saberes e fazeres ancestrais, são essenciais na vida dessas crianças e de suas famílias, nas suas territorialidades e na construção da "identidade territorial" (HAESBAERT, 2014). As famílias que ainda preservam a língua pomerana, usam-a em casa e ensinam essa sua língua materna com todo um legado ancestral a seus filhos e filhas, mantêm sua identidade pomerana mesmo num novo território.

Em seus "territórios tradicionais pomeranos", essas crianças produzem, reproduzem e ressignificam uma pluralidade de culturas infantis interseccionadas com a origem étnica, língua materna, cultura, territórios, idade, classe social, gênero, sexo, raça, religião. A expressão "culturas infantis", neste texto, é usada no sentido atribuído pelo sociólogo brasileiro Florestan Fernandes (1979). Em pesquisa realizada na década de 1940 junto com os grupos infantis no Bairro Bom Retiro, em São Paulo, o autor reconhece a diversidade étnica, cultural e linguística da sociedade brasileira. Afirmava a existência das culturas infantis construídas pelas próprias crianças no seio da cultura adulta, concebida não como mera reprodução desta, mas como espaço de reinvenção e de transformação. Nessa ótica, assevera Fernandes (1979, p. 126) que:

Os próprios imaturos também elaboram, é óbvio, parte dos elementos de seu patrimônio cultural. Alguns desses elementos foram, mesmo, estruturados sobre moldes fornecidos pela vida interativa da "gente grande". Essas criações, todavia, se institucionalizaram, posteriormente, podendo ser aprendidas nos grupos infantis, como acontece com os elementos aceitos da cultura do adulto.

Para Fernandes (2004), o processo de formação das culturas infantis é constituído por elementos aceitos da cultura do adulto e por elementos elaborados pelas próprias crianças. Ou seja, as próprias crianças também elaboram parte dos elementos de seu patrimônio cultural. As crianças internalizam, reinterpretam, ressignificam e difundem valores, modos de vida, normas, modelos de comportamentos, práticas sociais do mundo macro e micro, nas relações que estabelecem com seus pares em contextos distintos, produzem suas culturas infantis.

No entanto, contraditoriamente, as crianças pomeranas e também de outros grupos migratórios vêm sofrendo um processo histórico de apagamento e silenciamento de suas infâncias em um país tão plural. A partir das nossas pesquisas (SILLER, 1999, 2011), realizadas nos espaços e tempos da educação infantil em Santa Maria de Jetibá, foi possível verificar que embora a língua pomerana fosse a mais usada pelas crianças pomeranas e por todo o seu grupo étnico, ao ingressarem nas creches e 
pré-escolas, elas encontravam um ambiente que utilizava majoritariamente o português.

Essas crianças, bem como suas famílias, foram acometidos pela imposição e opressão de uma onda de políticas nacionalistas e colonialistas logo após sua chegada ao território brasileiro. Viam-se desterritorializadas em seus aspectos culturais, sociais, econômicos, linguísticos, ambientais, principalmente pelo sentimento de "estranhamento", de estar "fora do lugar". Por meio dessas políticas, a xenofobia tornouse uma prática comum, geradora de estigmas, estereótipos e preconceitos vinculados à origem étnica, de origem territorial, de uso da língua materna. Isso desenvolveu nessas crianças um processo de desvalorização, um sentimento de inferioridade, principalmente em relação àquelas que vivem na cidade.

A xenofobia é descrita pelo Alto Comissariado das Nações Unidas para os Refugiados (ACNUR), como: "Atitudes, preconceitos e comportamentos que rejeitam, excluem e frequentemente difamam pessoas, com base na percepção de que eles são estranhos ou estrangeiros a comunidades, sociedade ou identidade nacional" (apud SANTOS, 2021, s/p).

As opressões étnicas, linguísticas, culturais, territoriais, de classe que operam simultaneamente, situando as crianças pomeranas em condições de desigualdades, serão analisadas a partir da abordagem teórico-metodológica da interseccionalidade, termo cunhado em 1989 por Kimberlé Crenshaw, ativista negra, feminista, ancorada na teoria crítica de raça. Atualmente, essa abordagem é utilizada, principalmente, por mulheres feministas negras e diz respeito a como cada pessoa sofre opressões com base nos diferentes eixos de subordinação em que se encaixa. A intersecccionalidade busca

\begin{abstract}
capturar as consequências estruturais e dinâmicas da interação entre dois ou mais eixos da subordinação. Ela trata especificamente da forma pela qual o racismo, o patriarcalismo, a opressão de classe e outros sistemas discriminatórios criam desigualdades básicas que estruturam as posições relativas de mulheres, raças, etnias e outras. Além disso, a interseccionalidade trata da forma como ações políticas específicas geram opressões que fluem ao longo de tais eixos, constituindo aspectos dinâmicos ou ativos do desempoderamento (CRENSHAW, 2002, p. 177).
\end{abstract}

Na perspectiva da intersecccionalidade, tais eixos de subordinação somente podem ser revelados quando considerados os efeitos das formas cruzadas de exclusão e marginalização, em analogia ao entrecruzamento dos intensos fluxos de tráfego nas avenidas de uma cidade:

Utilizando uma metáfora de intersecção, faremos inicialmente uma analogia em que os vários eixos de poder, isto é, raça, etnia e classe, constituem as avenidas que estruturam os terrenos sociais, econômicos e políticos. É através delas que as dinâmicas do desempoderamento se movem. Essas vias são, por vezes, definidas como eixos de poder distintos e mutuamente excludentes. $\mathrm{O}$ racismo, por exemplo, é distinto do patriarcalismo, que, por sua vez, 
SILLER, R. R.

é diferente da opressão de classe. Na verdade, tais sistemas, frequentemente, se sobrepõem e se cruzam, criando intersecções complexas nas quais dois, três ou quatro eixos se entrecruzam. As mulheres racializadas frequentemente estão posicionadas em um espaço onde o racismo ou a xenofobia, a classe, o gênero se encontram. Por consequência, estão sujeitas a serem atingidas pelo intenso fluxo de tráfego em todas essas vias. As mulheres racializadas e outros grupos marcados por múltiplas opressões, posicionadas nessas intersecções em virtude de suas identidades específicas, devem negociar o tráfego que flui através do cruzamentos (CRENSHAW, 2002, p. 177).

Carla Akotirene (2018, p. 92), mulher negra, explica que, entendida como uma ferramenta teórico-metodológica, a importância da interseccionalidade não se reduz à identificação das interações dos marcadores sociais da diferença, referindo-se à localização dos pontos de intersecção entre eles para se pensar múltiplas exclusões e, ao mesmo tempo, estratégias e respostas para as desigualdades, com o reconhecimento de que algumas opressões são mais dolorosas.

É com essa perspectiva que serão analisadas as causas da xenofobia que afetam as crianças pomeranas. Essa análise se dá com base em marcadores de exclusão, tais como sua vinculação étnica, linguística, cultural, territorial, de classe, e direciona o olhar tanto para a exclusão promovida na Europa, continente de origem desses imigrantes, quanto no Brasil, onde ocorreu sua reterritorialização. ${ }^{2}$

Do lado da Alemanha, o nacionalismo e o imperialismo capitalista agiram simultaneamente e puseram vários povos germânicos diante da dura alternativa de se desprenderem de vínculos étnicos e linguístico-culturais ancestrais, migrando para outras regiões do mundo. No processo de unificação da Alemanha (1871), na busca pela ampliação do domínio político e econômico da nova nação, tentativas foram feitas no sentido de converter os diversos povos germânicos na categoria de "alemães".

No Brasil, a supremacia ideológica da cultura alemã também foi notada, apresentando-se como negadora das demais culturas desde o início da colonização. Em função disso, grupos de imigrantes tão heterogêneos, que viviam em seus núcleos coloniais segundo suas próprias culturas, língua, religião, formas de ser, de viver, entre os quais estavam os pomeranos, eram referidos como "alemães".

Em Santa Maria de Jetibá, essa política contou com a participação da Igreja Luterana e das escolas. Os pastores que atuavam na região vinham da Alemanha e, na língua alemã, realizavam atividades como os cultos e catecismo para as crianças, jovens, adultos, idosos que só falavam a língua pomerana. Também a bíblia e os hinários eram editados em alemão. A língua alemã também era a utilizada nas escolas paroquiais.

Tal política de negação das especificidades do povo pomerano intensifica-se no contexto da Segunda Guerra Mundial e, aqui no Brasil, esbarra com a ideologia nacionalista de Getúlio Vargas no período da ditadura do Estado Novo (1930-1945). Vargas impôs a necessidade de tornar o Estado brasileiro homogêneo: uma língua, uma cultura, uma religião, para garantir a continuidade da constituição de nação. Com essa política instituída, todos os imigrantes 


\begin{abstract}
[...] deveriam aprender o português, expressar-se somente nessa língua e esquecer a sua cultura de origem. As escolas mantidas pelas diversas comunidades imigrantes são fechadas ou nacionalizadas, as reformas de ensino vão aos poucos implantando uma base comum curricular para todo o país" (BAHIA; SANTOS, 2016).
\end{abstract}

Ainda hoje, notam-se resquícios da força impositiva dessa política nacionalista, que se materializou em um processo histórico de colonização cultural, étnica e linguística perpassado por xenofobia e intolerância em relação à diversidade. Por um lado, tal política nega a importância da língua materna das crianças pomeranas como elemento constitutivo de suas identidades, do mesmo modo que promove o silenciamento e o apagamento de tantas outras línguas faladas no Brasil. Dentre tantos outros direitos, tal política retirou das crianças pomeranas, e de tantas outras, o direito mais básico de qualquer ser humano, o de falar e agir nos espaços públicos na sua língua materna, o direito de conhecer a história ancestral, saberes e práticas sociais do seu grupo étnico. Constituiu-se em um dispositivo que selecionou quem tinha o direito à voz e quem devia ser silenciado.

Xenofobia, preconceito, discriminação marcam as identidades culturais das crianças pomeranas, que foram submetidas a um processo de inferiorização de sua cultura, ocasionando inclusive, processos de apagamento de sua própria língua. As crianças pomeranas, bem como suas famílias, sentiam-se estrangeiras em sua própria terra de nascimento e na qual ainda vivem e, com isso, aprendiam a ter vergonha de sua língua, de seus costumes, de suas práticas sociais, de suas experiências vivenciadas em seu território, interiorizando a concepção de que sua cultura é inferior e que tem menos valor. Enfim, o que se percebe é que a diversidade étnica, linguística e cultural vai cedendo lugar ao padrão cultural, em geral, associado à cultura dominante, estabelecida como uma única cultura, a hegemônica, talvez por considerá-la superior, ou originária, própria do nosso país.

A perspectiva da interseccionalidade contribui para que a compreensão das opressões como mutuamente constitutivas das formas de falar, de ser dessas crianças pomeranas e que não podem ser compreendidas apenas de forma independente. Etnia, cultura, língua, território são marcadores interligados de tal forma, que não há como caracterizá-los separadamente, isso porque uma língua está sempre ligada a uma etnia, uma cultura e a um território, dos quais a criança faz parte.

Desterritorializadas de seus locais de origem, as crianças pomeranas, ainda hoje em suas territorialidades, cotidianamente são incitadas a abrirem mão de suas especificidades, que as diferenciam, e a se apresentarem como sujeitos hegemônicos. Com predominância da língua portuguesa nas instituições de educação infantil, elas aprendem desde cedo a acreditarem que são monolíngues e, o pior, passam muitas vezes a ter vergonha de seu território, do seu grupo étnico, de sua cultura.

Percebe-se que, quanto mais uma criança se desviar do padrão normativo imposto por essa sociedade que não se reconhece pluriétnica, pluricultural e plurilíngue, mais ela sofrerá xenofobia e mais opressões. Assim ocorre com as crianças pomeranas e/ou de outros grupos étnicos, culturais e linguísticos, cujas diferenças em relação ao 
SILLER, R. R.

padrão justificaria seu posicionamento em uma hierarquia que as submete a condições de desigualdades.

\title{
CONSIDERAÇÕES FINAIS
}

Nesse contexto de hierarquização cultural, xenofobia e exclusão, pergunto: como nós, sujeitos adultos, profissionais da Educação Infantil, podemos ajudar as crianças migrantes, em especial, as crianças pomeranas, em suas territorialidades? Qual a nossa responsabilidade ético-político com essas crianças? Considerada como primeira etapa da educação básica conforme a Lei de Diretrizes e Bases da Educação Nacional, Lei n.9394/96, a educação infantil deve ser oferecida em creches e pré-escolas ou entidades equivalentes com a finalidade de promover "o desenvolvimento integral da criança de até 5 (cinco) anos, em seus aspectos físico, psicológico, intelectual e social, complementando a ação da família e da comunidade" (Art. 29, Redação dada pela Lei n.12.796, de 2013). Tendo em vista que a ação da família e da comunidade deve ser complementada pela ação das creches e pré-escolas, destacamos a importância de contemplar um conjunto de práticas que busquem articular as línguas faladas por essas crianças, os saberes, fazeres e experiências vivenciadas em seus territórios pomeranos, superando assim, práticas hierarquizadas que têm contribuído para legitimar múltiplas desigualdades desde a Educação Infantil.

Essas reflexões nos conduzem ao conceito de responsabilidade em Hannah Arendt (2002). Ser professor de Educação Infantil exige mais do que cuidar e educar as crianças pequenas, exige de nós, adultos, assumirmos a responsabilidade de nos colocarmos em ação para irromper essa cadeia de acontecimentos que tem assolado a vida das crianças pomeranas e de tantas outras de grupos étnico, linguístico e cultural diferenciados, afetadas por práticas de xenofobia, de preconceito de classe, de origem territorial, de uso de sua língua materna etc.

Exige de nós, adultos, assumirmos a responsabilidade pelo mundo para apresentá-lo a todas as crianças que chegam a este mundo para trazer o novo, para iniciar algo que ainda não existe. Responsabilizar-se pelo mundo significa "tomar nas próprias mãos, com a autoridade de quem é educador, o compromisso pelo cuidar do futuro e isso implica respeitar o passado" (ARENDT, 2002, p. 239). Com essa responsabilidade, nós, adultos, apresentamos a essas crianças tudo o que sabemos sobre o mundo, apontamos fatos e falamos sobre a realidade. E dizemos: eis aqui o nosso mundo! É com essa responsabilidade para com esse grupo de crianças migrantes que nós, adultos,

\begin{abstract}
decidimos se amamos nossas crianças o bastante para expulsá-las de nosso mundo e abandoná-las a seus próprios recursos e, tampouco arrancar de suas mãos a oportunidade de empreender alguma coisa nova e imprevista para nós, preparando-as em vez disso com antecedência para a tarefa de renovar um mundo comum (ARENDT, 1992, p. 247).
\end{abstract}

Ainda tendo Arendt como referência, creditamos nossas esperanças ao "milagre", não sob a ótica religiosa, do sobrenatural, da crença ou da superstição, mas no "milagre do novo" que está embutido em nossa capacidade de agir, de começar algo 
ovo, de inaugurar novos mundos (ARENDT, 1992), tendo como horizonte os valores mais elevados da humanidade: o bem comum e a felicidade pública. Os resultados dependerão da intensidade de mobilização, sensibilização e empenho de todos(as) nós.

Artigo recebido em: 31/03/2021

Aprovado para publicação em: 28/05/2021

\section{MIGRANT CHILDHOODS, EARLY CHILDHOOD EDUCATION, TERRITORIALITIES: THE MOVEMENTS OF DETERRITORIALIZATION AND RETERRITORIALIZATION OF THE POMERANIAN CHILDREN}

ABSTRACT: This paper, written in the form of essay, endeavors to understand the movements of de-territorialization of the Pomeranian children of their territory of origin, Pomerania, and reterritorialization, in their territory of destination, in this case, Santa Maria de Jetibá (ES). The territory is understood based on Sayad (1998) and Haesbaert (2014, 2020), in an integrative perspective. The text highlights de- territorialization as a process that is part of the migratory movements in which Pomeranian children participate. It points out that it is important that the debate on early childhood education include migrant children, particularly the Pomeranian ones, so that they can recognize themselves with their ancestral language, skills and knowledge, overcoming hierarchical practices that have contributed to legitimize multiple inequalities since this first stage of basic education.

KEYWORDS: Pomeranian Children. Immigration. Territoriality.

INFANCIAS MIGRANTES, EDUCACIÓN INFANTIL, TERRITORIALIDADES: LOS MOVIMIENTOS DE DESTERRITORIALIZACIÓN Y RETERRITORIALIZACIÓN DE NIÑOS POMERANOS

RESUMEN: Este artículo, en forma de ensayo, busca comprender los movimientos de desterritorialización de los niños pomeranos de su territorio de origen, Pomerania, y de reterritorialización, en su territorio de destino, en este caso, Santa María de Jetibá (ES). El territorio se extiende a partir de Sayad (1998) y Haesbaert $(2014,2020)$, en uma perspectiva integradora. EI texto destaca la desterritorialización como un proceso que forma parte de los movimientos migratorios en los que participan los niños de Pomerania. Señala la importancia del debate sobre la educación infantil para incluir a los niños migrantes, en especial a los pomeranos, para que se reconozcan con SUS lenguas, prácticas y conocimientos ancestrales, superando practicas jerárquicas que han contribuido a legitimar múltiples desigualdades desde esa primera etapa de la educación básica.

PALABRAS CLAVE: Niños de Pomerania. Inmigración. Territorialidad. 


\section{NOTAS}

1 - Município localizado na Região Centro-Serrana do Espírito Santo, com extensão territorial de $735 \mathrm{~km}^{2}$, altitude de 734 metros e 39.356 habitantes, dos quais 25.797 residem no meio rural $(65,55 \%)$ e 13.559 (34,45\%), no meio urbano (IBGE, 2016).

2 - Em 1817, a Pomerânia tornou-se uma província do Reino da Prússia, que foi um Estado independente de 1701 até 1871, quando ocorreu a união dos estados teutônicos sob seu domínio (Guerra Franco-Prussiana), criando-se o Império Alemão. Antes da unificação, iniciou-se um movimento migratório impulsionado pela pobreza e conflitos na região, a partir do qual vieram para o Brasil, notadamente, para o Espírito Santo e para estados do Sul do país, pomeranos da Pomerânia Oriental, que hoje integra o território da Polônia. A maioria era formada por empobrecidos e desprovidos da propriedade da terra. Com a derrota da Alemanha na Segunda Guerra Mundial (1945), os territórios em que estava subdividida a Pomerânia, Vorpommern (Pomerânia Ocidental) e Hinterpommern (Pomerânia Oriental), foram distribuídos, respectivamente, para a Polônia e a Alemanha. No fim do conflito, a população pomerana foi expulsa pelo Exército Vermelho e teve de deixar sua terra natal às pressas. A maior parte fixou residência na Alemanha, enquanto outros emigraram para os Estados Unidos e Austrália. Assim, a partir de 1945, a (antiga) Pomerânia não mais existe como unidade geográfica. No entanto, é importante salientar que os(as) imigrantes pomeranos(as) chegaram ao Espírito Santo antes de a Alemanha tornar-se um Estado-Nação (TRESSMANN, 2005).

3 - "A agricultura familiar é a constituída pelo trabalho familiar e também pelo assalariamento temporário, por exemplo, nos períodos de safra; [...] é reconhecida pela sua produtividade (especialmente de alimentos), por suas iniciativas de reorganização do trabalho e da produção, através da cooperação, e por sua resistência histórica na sociedade moderna" (FERNANDES; CERIOLI; CALDART, 2013, p. 32-33).

\section{REFERÊNCIAS}

AKOTIRENE, C. O Que é Interseccionalidade. Minas Gerais: Editora Letramento, 2018.

ARENDT, H. Entre o Passado e o Futuro. 3. ed. São Paulo: Editora Perspectiva, 1992.

ARENDT, H. O que é política? 3. ed. Rio de Janeiro: Bertrand Brasil, 2002.

BAHIA, Joana. SANTOS, Miriam (orgs). Um olhar sobre as diferenças - a interface entre projetos educativos e migratórios. E.book. Oikos editora. 2016. São Leopoldo.

BRASIL. Lei n 12.796, de 4 de abril de 2013. Altera a Lei n० 9.394, de 20 de dezembro de 1996, que estabelece as diretrizes e bases da educação nacional, para dispor sobre a formação dos profissionais da educação e dar outras providências. Disponível em: http://www.planalto.gov.br/ccivil_03/_ato2011-2014/2013/lei//12796.htm. Acesso em: 14 jun. 2020. 
CRENSHAW, K. Documentos para o encontro de especialistas em aspectos da discriminação racial relativos ao gênero. Revista de Estudos Feministas, Santa Catarina, v. 10, n. 1, p. 171-188, jan. 2002.

FERNANDES, F. As Trocinhas do Bom Retiro: contribuição ao estudo folclórico e sociológico dos grupos infantis. In: FERNANDES, F. (Org.). Folclore e mudança social na cidade de São Paulo. 2 ed. Petrópolis: Vozes, 1979.

FERNANDES, B. M.; CERIOLI, P. R.; CALDART, R. S. Primeira Conferencia Nacional "Por uma educação básica do campo" texto Preparatório. In: ARROYO, M. G; CALDART, R. S.; MOLINA, M. C. (Org.). Por uma Educação do Campo. 4 ed. Petrópolis: Vozes, 2009.

HAESBAERT, R. Viver no limite: território e multi/transterritorialidade em tempos de insegurança e contenção. Rio de Janeiro: Bertrand Brasil, 2014.

HAESBAERT, R. O mito da desterritorialização: do fim dos territórios à multiterritorialidade. Rio de Janeiro: Bertrand Brasil, 2004.

HALL, S. A questão multicultural. In: HALL, S. (Org.). Da diáspora: identidades e mediações culturais. Belo Horizonte: UFMG, 2003.

IBGE. Infográficos: dados gerais do município de Santa Maria de Jetibá. Disponível em: http://www.cidades.ibge.gov.br/painel/painel.php?lang=\&codmun=320455\&search=es pirito-santo\%7Csanta-maria-de-jetiba\%7Cinfograficos:-dados-gerais-do-municipio. Acesso em: 8 fev. 2021.

KRENAK, A. Ideias para adiar o fim do mundo. Rio de Janeiro: Companhia das Letras, 2019.

MAUSS, M. Sociologia e antropologia. São Paulo: Cosac \& Naify, 2003.

MONDARDO, M. Conflitos territoriais entre Guaranis Kaiowás, paraguaios e "gaúchos": a produção de novas territorialidades no Mato Grosso do Sul. 2012. 215 f. Tese (Doutorado em Geografia). Programa de Pós-Graduação em Geografia, Universidade Federal Fluminense, Niterói, 2012.

SAYAD, A. A imigração ou os paradoxos da alteridade. São Paul: EDUSP, 1998.

SAYAD, A. O retorno: elementos constitutivos da condição do imigrante. TravessiaRevista do Imigrante, São Paulo, v. 1, n. esp., p. 2-17, jan./abr. 2000.

SANTOS, T. Medo do que é diferente ou desconhecido. Educa + Brasil, fev. 2021. Disponível em: https://www.educamaisbrasil.com.br/enem/sociologia/xenofobia. Acesso em: 8 fev. 2021. 
SILLER, R. R.

SARTRE, J. P. Prefácio. In: FANON, F. (Org.). Os condenados da Terra. 2. ed. Rio de Janeiro: Civilização Brasileira, 1961. p. 23-48.

SILLER, Rosali Rauta. A construção da subjetividade no cotidiano da educação infantil. 1999. 214p. Dissertação (Mestrado em Educação) - Programa de Pós-Graduação em Educação, da Universidade Federal do Espirito Santo. 1999.

SILLER, Rosali Rauta. Infância, Educação Infantil, Migrações. 2011. 261p. Tese (Doutorado em Educação) - Programa de Pós-Graduação em Educação, Faculdade de Educação da Universidade Estadual de Campinas, Campinas, 2011.

TRESSMANN, I. Da sala de estar à de baile: estudo etnolinguístico de comunidades camponesas pomeranas do estado do Espírito Santo. 2005. 250 f. Tese (Doutorado em Linguística) - Programa de Pós-Graduação em Linguística, Universidade Federal do Rio de Janeiro, Rio de Janeiro, 2005.

TURRA, M. de L. Escola, homogeneidade e diversidade cultural. In: GONÇALVES, M. A. R. (Org.). Educação e Cultura: pensando em cidadania. Rio de Janeiro: Quartet, 1999.

Rosali Rauta Siller: Professora do Departamento de Teoria e Práticas de Ensino-DTEPE do Centro de Educação da Universidade Federal do Espírito Santo-UFES. Professora do Curso de Licenciatura em Educação do Campo. Possui Graduação em PedagogiaOrientação Educacional pela Universidade Federal do Espírito Santo (1980), Graduação em Pedagogia- Supervisão Escolar pela Faculdade de Filosofia Ciências e Letras de Colatina (1987), Mestrado em Educação pela Universidade Federal do Espírito Santo (1999) e Doutorado em Educação pela Universidade Estadual de CampinasUNICAMP (2011). Pós-doutora pelo Programa de Pós Graduação em EducaçãoPPGE/UFES.

Orcid: https://orcid.org/0000-0002-5296-8908

E-mail: rauta13@gmail.com

Este periódico utiliza a licença Creative Commons Attribution 3.0, para periódicos de acesso aberto (Open Archives Initiative - OAI). 